\title{
Rethinking Retail Experience
}

\author{
Jonathan Rez \\ Central Saint Martins College of Art and Design, University of the Arts London \\ info@rez.com.au
}

\begin{abstract}
This project set out to explore how retail environments can offer experiences that are rewarding in more ways than they currently do. Using the Selfridges department store in London as a testing ground, a concept for a character-driven emergent narrative iPhone app has been developed.
\end{abstract}

The Selfridges Trails app enables shop visitors to engage with store content in new and more meaningful ways; from following the trail of a celebrity style-icon through to curating their own trail, which can be shared with other app users, or with friends on popular social networks.

Over time, as individual user generated content increases within the app, its ability to meet varying needs of shop visitors would improve.

The app converges current technology in locative media and online social networking with contemporary emergent narrative theory. Further research is proposed into how such an app may be used in the future to drive the physical layout and design of experience spaces.

Retail environment, Retail Theatre, Emergent narrative, Location based service, Mixed reality, Online Social Networking, User generated content, Experience design

\section{SYNOPSIS}

As people are increasingly shifting to online shopping, the relevance of physical retail spaces decreases as they become less significant for the shop visitor and less cost effective for the retailer to maintain. It is estimated that by $2013,10 \%$ of shopping will be conducted on-line (Datamonitor, 2009). Will brands have to let go of physical touchpoints, or is there room to evolve the types of experiences offered within a department store, in order for them to retain relevance in a future world, both for the brand and the visitor?

Coming from a fascination with the individual and collective meaning surrounding things - objects and places - and our experience of them, this project started by posing questions like "why is it that a retail environment, with its richness of things, only being used for shopping?"; "Is there not a potential to do more with the space and its content?"; "If museums are looking at ways to improve sales in the museum shop, what if retailers were to look at ways to improve the cultural experience surrounding things in the store?".

Retail Brands have much to gain from rethinking retail experience to achieve visitor take-out that could be richer, more memorable, more rewarding and which can enhance the respect and trust of the consumer-visitor.

This project set out to explore the potential for new types of experiences in retail environments multilayered experiences that do not necessarily entail financial transactions; experiences that could pay off long term as brands strengthen customer relations and loyalty. Is there potential to reconceive the retail environment as a space where people go not just for shopping? Perhaps a recreation space, a playground for fun activities or a learning environment.

The currently prevailing Retail Theatre paradigm was reviewed and evaluated with focus on the levels of agency afforded to customers.

The final outcome of this exploration was the development of a concept for a smartphone app that facilitates a new genre of multilayered experiences at Selfridges, a department store in London. The app is a product-based, characterdriven emergent narrative system, through which shop visitors would be able to follow the trail of a celebrity/style-icon or curate their own trail, which would be shared with other app users, and with friends on popular social networks. It combines 
traditional visitor experiences with contemporary online social network features, blended with a touch of practical features that shoppers would expect from such an app.

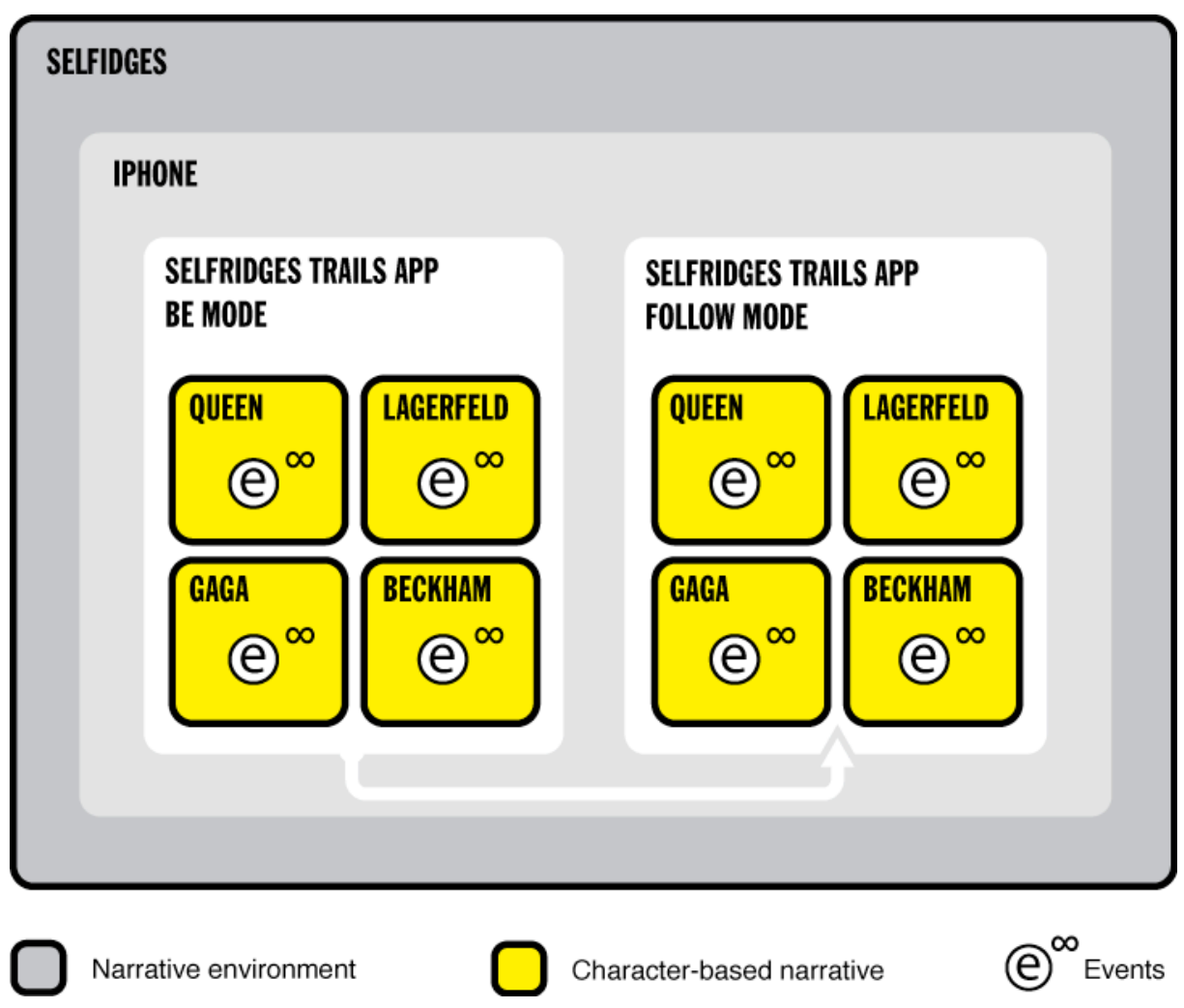

Figure 1: Narrative framework behind the Selfridges Trails app

\section{FUTURE IMPLICATIONS}

While this project was designed for a retail environment, it can quite comfortably be ported to a museum environment, since while it facilitates character-based narratives, the events of the story are based around things suspended in space, both artefacts and places. This suggests that any interpretative environment could benefit from the concept, be it an historical building or a whole city. For example, A visitor to London curating their own trail, in the shoes of Queen Elizabeth the $1^{\text {st }}$, Jack the Ripper or David Beckham. The unique opportunity lies in the thematic framework: usergenerated, character-driven experience, as opposed to top-down taxonomies and content.

Interesting applications of this location based service could emerge over time, as people's spaceuse characteristics are recorded and become available for analysis by site-owners. A newfound understanding of audiences can be used to determine the placement of things in an environment and its scenography to enrich and diversify visitors' mixed-reality experiences.

\section{REFERENCES}

Datamonitor. (2009) 'Multichannel Retail: Using Integrated Technology to Achieve Cross-Channel Brand Consistency', p. 6.

Harris, et al. (2001) 'Customer participation in retail service: lessons from Brecht', International Journal of Retail \& Distribution Management, vol. 29, no. 8, pp. 359-369.

Larsson, E. (2005) 'Spectator or Participant', Interacting Arts, International Issue pp. 4-9.

Louchart, et al. (2008) 'Purposeful Authoring for Emergent Narrative', Proceedings, 1st International Joint Conference on Interactive Digital Storytelling, pp. 273-284. 